\title{
Phage therapy: progress in pharmacokinetics
}

\author{
Muhammad Imran Qadir*, Tahira Mobeen, Ardas Masood
}

Institute of Molecular Biology \& Biotechnology, Bahauddin Zakariya University, Multan, Pakistan

\begin{abstract}
The concept of phage therapy exists in the history and it has been ignored for a long time, but the consequence of drug resistance in pathogen bacteria has forced the forgotten kingdom of phage therapy to be re-explored. However, for the successful implementation and acceptance of phage therapy worldwide, the number of factors need to be addressed. In pharmacology of phage therapy, pharmacodynamics is a straightforward concept, on the other hand, owing to the unique feature of phages to replicate and their high sensitivity, pharmacokinetics is rather complex. In this review, we have discussed pharmacokinetics and some recent advances in delivery systems as to achieve the therapeutically effective concentrations of phage in their activated form.
\end{abstract}

Keywords: Phage therapy/pharmacology. Pharmacokinetics. Delivery systems

\section{INTRODUCTION}

Bacterial resistance against antibiotics has considerably peaked in recent years; the menace of resistance has given birth to a new range of extended spectrum pathogens. The failure of antibiotic and chemotherapy for eradication of bacteria has forced scientists to look for alternative biological methods. One such approach is the use of lytic bacteriophages against pathogen bacteria. Felix d'Hérelle, the discoverer of bacteriophages, first introduced the idea of phage therapy in the beginning of the $20^{\text {th }}$ century (Sulakvelidze, 2005). However, the initial trials of phage therapy produced inconsistent results to be considered over antibiotics. Even though, some US pharmaceutical companies produced some commercial phage products in 1930s. Subsequently, the Soviet Union developed phage therapy against diseases like diarrhea and wound infections (Sulakvelidze, Alavidze, Morris, 2001). In Russia, several phage formulations are now being sold as registered medicine.

Phage therapy to combat bacterial infections is garnering attention for the second time in 100 years, but solid clinical support for its widespread use is still lacking. Before proper human clinical trial of phage therapy can be considered, there are a number of issues that are

\footnotetext{
*Correspondence: M. I. Qadir. Institute of Molecular Biology \& Biotechnology, Bahauddin Zakariya University, Multan, Pakistan-6000. Phone: +92-3016515613. E-mail: mrimranqadir@hotmail.com
}

considered necessary to be addressed (Knoll, Mylonakis, 2014). There are multiple factors that direct the therapeutic efficacy of phage therapy, for example, for convenient oral application; the phage must endure gastrointestinal route. Furthermore, phage should stay for a sufficient period of time and reach the infected tissue with high enough titer to achieve its lytic activity. Moreover, for safety, phage particles should not impose any side effects and must not carry any virulence gene, as they might get transferred to the target host.

The process of using phages for therapy is conceptually simple; although, along with the simplicity comes the consequences of a certain degree i.e. complex pharmacokinetics. This complexity is the phages' ability to replicate their number, which is a result of antibacterial activity, precisely where target bacteria are present. As with any antimicrobial agent, the key step is to reach bacterial targets in enough loads to ensure that a minimum active concentration is achieved. This can be attained either through the direct application of phages to the infection site or via systemic delivery (Chan, Abedon, Loc-Carrillo, 2013).

\section{Phage therapy pharmacokinetics}

There is a handful of data that entails pharmacology of bacteriophage therapy, with a very few that emphasize on the pharmacokinetics of phage therapy. Pharmacology deals with the drug and body interactions, it is subdivided 
in pharmacokinetics-body's impact on drug- and pharmacodynamics-drugs impact on the body.

Pharmacokinetics accounts for a drug's ability to reach sufficient concentrations in the locality of targeted tissues, as it is very important to bring about the pharmacodynamic effects of the drug. This pharmacokinetics summarizes into absorption, distribution, metabolism and excretion. Absorption is drug movement into the blood. From the blood the drug is transported to the body tissues this phenomenon is known as distribution. Once reached the target tissues, the drug is metabolized and modified into its active form, the last step is excretion of drugs from the body. All these pharmacokinetic features play their role in both increasing and reducing drug densities. For example, both absorption and distribution result in the decrease in drug densities owing to drug dilution, which at the same time might increases drug density in the particular body organ (Abedon et al., 2011). Depending upon the pharmacokinetics different means of drug delivery are adopted. The delivery route of a drug is selected on a number of factors; a) target tissue, b) sensitivity of drug to body enzymes, immunity, $\mathrm{pH}$ etc) drug in take routine, d) patient's convenience.

In phage therapy, metabolism can work two ways; either inactivation of phage particles due to contact with the immune system or activation followed by replication of phages. Moreover, excretion results in decreased drug densities, the other way round, it can serve to increase phage concentration in organs like kidney and bladder, which may prove therapeutically beneficial (Vandenheuvel, Lavigne, Brüssow, 2015).

Whatever the case may be, the success of phage therapy depends on enough phage generations in the locality of the target to bring about the eradication of pathogen bacteria from the body. The increase in phage concentration to sufficient densities can be attained by two means. Firstly, with in situ replication, that is called active treatment, or as a result of pharmacologically conventional dosing, the passive treatment. The ways of rising phage concentration must be adequately stout so that they compensate the mechanism of phage reduction. The goal is thus to achieve minimum phage concentration at the target site, that is necessary for the desired levels of bacterial eradication. Also, worth mentioning is the necessity for phage preparations to be adequately purified (e.g., to remove bacterial debris). Such purification should be substantial (e.g., to remove most bacterial components, including endo-toxins), particularly when phages are to be delivered directly to an animal's systemic circulation (Chan, Abedon, Loc-Carrillo, 2013).
Recently, the turn back to phage therapy has led the scientists to evaluate the pharmacokinetic efficacy of phage therapy. One such investigation was done in Phage Therapy Center at the Institute of Immunology and Experimental Therapy, the Polish Academy of Sciences. Scientists have examined the estimated cost of treating staphylococcal infection in which good clinical outcome of the bacteriophage therapy was shown. classically, the phages are delivered orally and/or locally in the form of phage lysates (Międzybrodzki et al., 2007). Moreover, the problem of phages to leave the blood stream and reach the infected tissues can be avoided by phage constructs with tissue-specific peptides, it will help the phages to reach the targeted organs (Górski et al., 2015).

Phage formulation is another important aspect of governing effective pharmacokinetics. Different formulation strategies are employed to increase the stability of phages. The no of active phages in a formulation is directly proportional to the efficacy of treatment. The table I summarize recent formulation strategies for the phage preparation.

\section{Routes of administration}

Various studies have been conducted on bacteriophage therapy to investigate the delivery routes, most studied being the parenteral and oral route of administration and both of them are systemic. On the other hand, non-systemic routes or local phage delivery systems are being investigated. The use of phage lysate for prevention of biofilm on medical equipment is also studied.

The varied concepts of pharmacokinetics requirement for phage to penetrate the target bacteria, the accomplishment of adequate phage concentration in the locality of the target, and ample antibacterial action against the target - are worth considering when treating various infections in both animal models and humans.

\section{Bacteriophages via parenteral delivery}

In phage therapy, parenteral delivery has proven to be the most successful of all delivery regimes; this success is explained by the maximum distribution and bioavailability of the administered phages.

A study was conducted on mice compromised by burn injury and subsequently infected by Psedumonas aeruginosa, the infected mice were treated with phage cocktail containing three different $P$. aeruginosa phages. Phages were given by three delivery routes; intramuscular, intravenous and intrasubcutaneous. The comparative 
Phage therapy: progress in pharmacokinetics

TABLE I - Phage formulation strategies

\begin{tabular}{|c|c|c|c|}
\hline Formulation strategy & Phage type & Use & Reference \\
\hline Liquid/ suspension & $\begin{array}{c}\text { ZF40, ZF49, Phage T4, BFC- } \\
1 \text { phage cocktail. }\end{array}$ & $\begin{array}{l}\text { Wound dressing, injectable, } \\
\text { food additives and nebulizers. }\end{array}$ & $\begin{array}{l}\text { (Borie et al., 2009; Golshahi } \\
\text { et al., 2008; Hoe et al., 2013; } \\
\text { Merabishvili et al., 2009; } \\
\text { Merabishvili et al., 2013) }\end{array}$ \\
\hline $\begin{array}{l}\text { Solid; Powdered, } \\
\text { microencapsulation, }\end{array}$ & $\begin{array}{c}\text { KS14, N-1, S-204, Sh-1, } \\
\text { KS-41, D3, F2, F-9, Felix01, } \\
\text { cocktails }\end{array}$ & $\begin{array}{l}\text { Inhalable powder, bandages, } \\
\text { tablets, pills }\end{array}$ & $\begin{array}{c}\text { (Hoe et al., 2013; Matinkhoo } \\
\text { et al., 2011; Ohtake et al., } \\
\text { 2010; Vandenheuvel et al., } \\
\text { 2013) }\end{array}$ \\
\hline Cream, oil-water emulsion & Staphylococcus phage K & $\begin{array}{c}\text { Can be used as a topical, } \\
\text { ointment }\end{array}$ & $\begin{array}{c}\text { (Esteban et al., 2014; } \\
\text { O'Flaherty et al., 2005) }\end{array}$ \\
\hline PEGylated & Felix01 & Injectable & (Veronese, Pasut, 2005) \\
\hline Amino acid substitution & $\begin{array}{c}\text { Agro1, Agro2, Agro3, Agro4, } \\
\text { W60 }\end{array}$ & Injectable & 54 \\
\hline
\end{tabular}

efficacies of these delivery routes were measured showing that the intravascular route provided the most significant defense against the infection (up to $87 \%$ ). Moreover, the dosage quantity of given phage cocktail was also important in attaining improved pharmacokinetics, the high dosage of phages was more effective (McVay, Velásquesz, Fralick, 2007).

Phage movement from one body section to another can greatly hurdle effective therapy. The parenteral and oral dosing primarily results in blood circulation. The absorption is expected to be more proficient through the parenteral route, i.e. there is a probability of less phage loss in parenteral delivery as compared to oral delivery. With oral dosing, phages must endure and pass the gastrointestinal zone, both of which are not the simple course of action. On the other hand, topical application minimizes associated losses of absorption and distribution, enhancing antibacterial activity of phages. Instillation, i.e. directly injecting phages in infection sites also minimizes the losses, though it is more restrained than topical application (Figure 1). (Abedon, 2015).

Similarly, another study, using Liposomes as a delivery vehicle for phage for the first time, used the intraperitoneal (IP) route of administration to explain the therapeutic and prophylactic potential of bacteriophage in a mouse model of lobar pneumonia caused by K. pneumoniae (Singla et al., 2015).

A similar study conducted previously, in which Bacteremia was induced in mice by IP injection of a strain of vancomycin-resistant Enterococcus faecium. A single IP injection of phage strain ENB6 was administered after 45 min of infection. The survival rate was shown to be $100 \%$. It was concluded that, when administered intravenously,
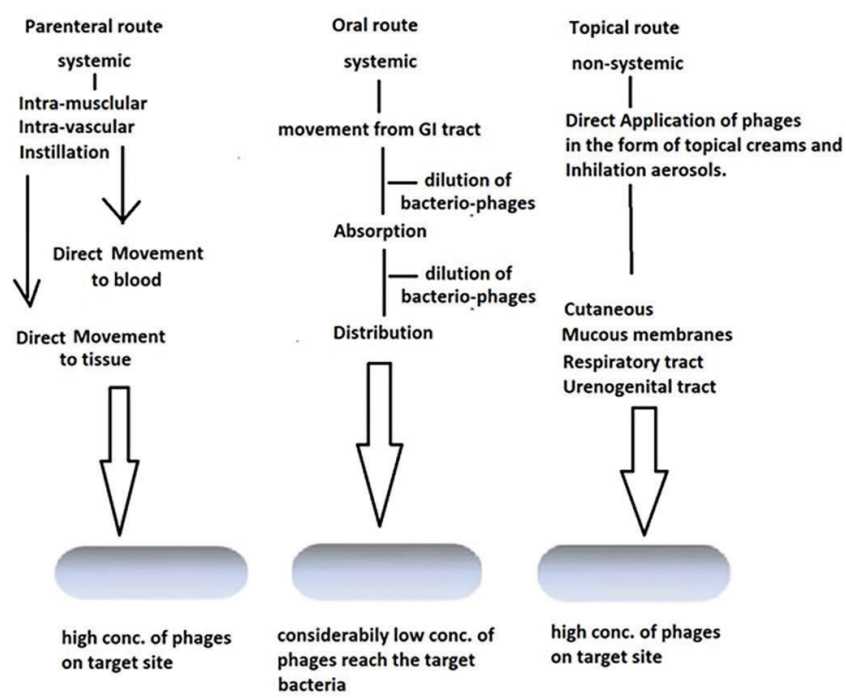

FIGURE 1 - Route of Administrations and pharmacokinetics.

phages can be efficient at clearing local infection and can be distributed and absorbed throughout the body (Biswas et al., 2002).

Most of the studies using $P$. aeruginosa delivered via the IP route suggested that the phages were rapidly distributed to the tissues and were delivered for a longer period of time than phages administered via the intrasubcutaneous or intramuscular route.

\section{Bacteriophages via oral delivery}

Bacteriophage delivery through oral administration suggests its success in treating gastrointestinal infection and, in rare cases systemic infections. The pathogen bacteria, which is located in the gut is mainly accessible 
to orally applied phages. However, there are drawbacks of the oral delivery system; primarily it's the deactivate ion of bacteriophages by the acidic environment of stomach. The sensitivity to the acidic environment varies for different bacteriophages, for some deactivation may occur. Hence, there is a need for the characterization of bacteriophage individually.

The gastric acid neutralization is done with the administration of some "stomach acid neutralizing agent" like sodium bicarbonate or bicarbonated mineral water (Qadir, 2015). Phages may be given orally three times a day before eating, as the PH is slightly less acidic at this time.

Some orally applied phages are absorbed into the circulation system. However, it depends on the characteristics of each individual phage (Oliveira et al., 2009). Some phages reside inside the gut lumen, they are also absorbed through the intestinal walls. The underlying mechanism of the viral translocation remain unclear, it is recommended that the number of factors control bacteriophage passage through intestinal walls, for example, phage concentration, capsid protein's specific sequences for interaction with the intestinal cell membrane and its interaction with immune cells within the gut.

For combating the problem of deactivation many preventive strategies can be applied. One such method is microencapsulation, for example, bacteriophage Felix O1 was microencapsulated in alginate-chitosan microsphere. This encapsulation appreciably increased the acidic endurance of phage under laboratory conditions designed to replicate in the pig gastrointestinal tract (Ma et al., 2008).

Recent encapsulation strategies are aimed at providing a delivery technology with improved efficacy of bacteriophage in oral application. Enteric polymers have been demonstrated to offer effective protection for bacteria against in vitro simulated gastric conditions; likewise, they might be used for the phage encapsulation.

Phage cocktail is another method to effectively deliver bacteriophages via oral administration. In an investigation, phage cocktail consisting of SP15, SP21 and SP22 bacteriophages was used against a strain of E. coli, with the most successful administration route being a daily oral dose of phages (Tanji et al., 2005).

Hence, studies show that bacteriophage can be absorbed efficiently into systemic circulation through oral administration. Nonetheless, absorption via oral delivery depends on the individual characteristics of each phage as well.

\section{Local delivery of phages}

The local delivery of phages is one of the successful administration regimes, and several reports are present in literature, most of them focusing wound healing. There has been development of hydro-gel and saturated formulations of bacterio-phages for wound healing. It has greatly increased the phage therapy's success in topical applications. Locally, phages can be applied on infected areas in the form of moist dressing (Qadir, 2015).

A commercially successful example of topical product is the Phagebioderm ${ }^{\circledR}$, it was developed by the Eliava Institute, Georgia. This formulation specifically targets $P$. aeruginosa, S. aureus and Streptococcus spp. It is a cocktail of antibiotics and bacteriophages saturated in stabilized hydrogel arrangement for topical application (Markoishvili et al., 1999). Currently, local phage therapy has also focused on other areas i.e. otic and oral applications.

\section{Topical administration of phages}

In topical form, the bacteriophage has been effective for the treatment of skin ailments. A study has been reported using bacteriophages to decrease the infection of chicken skin by Salmonella and Campylobacter spp. The MOI of phages were assessed i.e. the effect of the ratio of phage particles to bacterial cells. Phages were applied at two different MOI, one at relatively higher MOI then other. The investigation showed that the efficiency of phage treatment was dependent on phage quantity. By increasing the MOI, increased bacterial eradication was observed (Goode, Allen, Barrow, 2003).

A recent report investigated the efficacy of phages against natural healing agents (aleovera and honey). The $K$. pneumoniae B5055-induced burn wound infection was treated with topical application of Klebsiella-specific phage Kpn5, on the other hand, with aleovera and honey. A survival rate of up to $96.66 \%$ observed with phage treatment in comparison to the death rate of $83.34 \%$ in the second group on the second day post treatment. One interesting finding was that the treatment with high titre of phage resulted in a long term solution to the infection and the low titre was ineffective, hence sufficient concentration of phages are crucial for the successful treatment (Kumari, Harjai, Chhibber, 2010).

\section{Octic administration of phage}

Data is available from clinical trials of bacteriophage therapy in chronic otitis caused by an extended spectrum strain of $P$. aeruginosa. The patients studied with an ear infection of $P$. aeruginosa. They were randomly divided into two groups, one receiving a single dose of Biophage- 
PA ${ }^{\circledR}$ and the second receiving placebo; the phages were given via octic administration. The patients followed up at 7,21 and 42 days after treatment. It was shown that the administration of this topical bacteriophage mixture successfully killed $P$. aeruginosa in the ear and improved the clinical manifestation of ear infectivity (Wright et al., 2009). A latest study, reporting clinical trial on canine for the treatment of $P$. aeruginosa otitis with bacteriophage cocktail, holds similar assures. Hence, this topical bacteriophage formulation is a potential candidate to be conveniently and effectively used against $P$. aeruginosa otitis in dogs (Hawkins et al., 2010).

Furthermore, phages are used in the form of suspension (Drops) for application to eye, middle ear and nasal mucosa (Qadir, 2015).

\section{Dental phage administration}

Number of papers and patent filing reports focus on the use of phages in combating dental infections. An investigation was carried out to assess the effect of bacteriophage on the viability of Enterococcus faecalis (ATTC 29212) in human dental roots. The teeth were divided in five groups, all were given different conc. of bacteriophages. A substantial reduction in bacterial growth was observed in all groups, which indicates the ability of phages to inhibit bacterial growth in teeth tubules. Hence phage therapy can be considered an alternative for root canal infection, which is otherwise intractable by conventional endodontic therapy (Paisano et al., 2004).

\section{Nebulizer inhalation of bacteriophage}

The most recent advances in the field of phage therapy have been inhalation technologies. In view of the success of bacteriophage therapy in both local and systemic applications, using bacteriophages to fight lung infections look promising. The development of modern inhalation and process technologies has allowed great advances in this field. Recently, nebulizers have been introduced to deliver bacteriophages to the lungs. A study focused on the efficiency of nebulizer delivery and the particle-size distribution of droplets (Golshahi et al., 2008). The nebulizer was shown to be successfully delivered the phage particles to the lungs. Moreover, further examination of in-vitro delivery of bacteriophages using the inhalation formulation of dry powder was done by the same group of scientist for treatment of cystic fibrosis pulmonary infections (Golshahi et al., 2011).

Another study was done indicating in-vivo efficacy of phage therapy for Burkholderia cepacia lung infections.
A mouse model of severe respiratory tract infection was used; the effect of treatment with a single phage strain on bacterial load and lung inflammation was examined. Mice were administered, either by intranasal inhalation or by IP injection. However, Bacterial concentration, macrophage inflammatory protein 2 (MIP-2) and tumor necrosis factor $\alpha(\mathrm{TNF}-\alpha)$ levels, were significantly reduced in the lungs of mice treated with IP-administered phages as compared to the inhalational administration (Carmody et al., 2010).A recent study suggests that $P$. aeruginosa isolated from the lungs of cystic fibrosis patients may become more susceptible, over the course chronic infections, to unassociated phages (Friman et al., 2013)

Many studies investigated the phage therapy against Pseudomonas aeruginosa in cystic fibrosis patients (James et al., 2015; Saussereau et al., 2014). The main element highlighted is the prospective of bacteriophage therapy in cystic fibrosis patients through inhalation. Certainly, the nebulizer route of administration is chosen for cystic fibrosis patients (Hraiech, Brégeon, Rolain, 2015).

\section{Instillation of phages}

A case study recently reported the treatment of a $67-$ year old woman through instillation of phage formulation to the bladder. The patient was hospitalized and $20 \mathrm{ml}$ Pyophage \#051007 was instilled directly into the bladder for 10 days with $12 \mathrm{~h}$ gap, with the catheter fasten for half an hour after each instillation. The data indicated that bacteriophage infection was self-sustaining and selflimiting, with the phage decreasing in number alongside the viable target organisms in which they replicated (Khawaldeh et al., 2011).

\section{Elimination}

After intraperitoneal administration, the level of bacteriophages decreased rapidly in first 8 to 12 hours and then gradually decreased and eventually disappeared in three days, depicts a pattern just like of two-compartmental model. The initial phase of the rapid decrease from 8 to 12 hours (considered as alpha-phase) is due to distribution of phages to the organs and second phase (considered as beta phase) is due to elimination of phages (Uchiyama et al., 2009). Although, the kinetics of blood clearance have had not been well described. So, for further development in therapeutic efficacy, information on bacteriophage blood kinetics is one of the most important criteria to determine optimal therapeutic approach.

Within 2 to 4 hours, a single oral dose results in the absorption of phages into the blood stream and to inner 
TABLE II - Administration routes of phage therapy adapted in different pre-clinical and case study in humans

\begin{tabular}{|c|c|c|c|}
\hline Administration route & Against & Results & References \\
\hline Intramuscular & $\begin{array}{l}\text { Meningitis in calves and } E \text {. } \\
\text { coli septicaemia in chickens }\end{array}$ & $\begin{array}{l}\text { Significant protection against } \\
\text { E. coli }\end{array}$ & $\begin{array}{c}\text { (Barrow, Lovell, Berchieri, } \\
\text { 1998) }\end{array}$ \\
\hline Intravenous & $\begin{array}{l}\text { Local and systemic disease } \\
\text { caused by Vibrio vulnificus } \\
\text { and } S \text {. aureus in animals }\end{array}$ & $\begin{array}{l}\text { Phage treatment was radically } \\
\text { reduced inflammation due to } \\
\text { infection }\end{array}$ & $\begin{array}{c}\text { (Abedon et al., 2011) } \\
\text { (Capparelli et al., 2007) }\end{array}$ \\
\hline intra-peritoneally & $\begin{array}{l}\text { lethal Staphylococcus aureus } \\
\text { infection in mice }\end{array}$ & $\begin{array}{l}\text { S. aureus -induced lethality } \\
\text { Suppressed }\end{array}$ & (Matsuzaki et al., 2003) \\
\hline Subcutaneous & $\begin{array}{l}\text { Lung abscesses in } \\
\text { rabbits and bronchiectasis } \\
\text { Staphylococcus aureus, } \\
\text { Proteus, and Streptococci }\end{array}$ & $92 \%$ survival was reported & $\begin{array}{c}\text { (Wills, Kerrigan, Soothill, } \\
\text { 2005) } \\
\text { (Sakandelidze, Meĭpariani, } \\
\text { 1974) }\end{array}$ \\
\hline Oral delivery & $\begin{array}{l}\text { gastrointestinal infections and } \\
\text { and rare cases of systemic } \\
\text { infections }\end{array}$ & $\begin{array}{l}\text { Titres of } E \text {. coli were } \\
\text { significantly reduced }\end{array}$ & (Tanji et al., 2005) \\
\hline Topical administration & $\begin{array}{c}\text { Skin infection. } \\
\text { K. pneumoniae induced burn } \\
\text { wound infection in mice }\end{array}$ & $\begin{array}{l}\text { Up to } 90 \% \text { survival rate as } \\
\text { compared to control group }\end{array}$ & $\begin{array}{c}\text { (Kumari, Harjai, Chhibber, } \\
\text { 2010) }\end{array}$ \\
\hline Octic route & $\begin{array}{c}\text { chronic otitis infection } \\
\text { of extended spectrum } P \text {. } \\
\text { aeruginosa }\end{array}$ & $\begin{array}{l}\text { P. aeruginosa counts were } \\
\text { significantly lower in the } \\
\text { phage-treated group }\end{array}$ & (Wright et al., 2009) \\
\hline Dental route & $\begin{array}{l}\text { Enterococcus faecalis } \\
\text { infection human dental } \\
\text { Roots } \\
\end{array}$ & $\begin{array}{l}\text { Reduce bacterial growth and } \\
\text { number in root canal }\end{array}$ & (Paisano et al., 2004) \\
\hline Inhalation & $\begin{array}{c}\text { Pseudomonas Staphylococcus } \\
\text { and lung infections }\end{array}$ & $\begin{array}{l}50 \% \text { reduction in required } \\
\text { ongoing antibiotic treatment }\end{array}$ & $\begin{array}{l}\text { (Golshahi et al., 2008; } \\
\text { Kvachadze et al., 2011) }\end{array}$ \\
\hline
\end{tabular}

organs in10 hours (Sulakvelidze et al., 2001). According to the data available, phages reside in human body and circulating system for a substantial time period. It was determined that reticulo-endothelial system is involved in elimination of bacteriophages from the human body. However, the possible role of innate immunity on elimination of bacteriophages is not clear.

\section{CONCLUSION}

Phage therapy is a promising alternative for the inadequacy of antibiotics and their ever-decreasing effectiveness. It is evident, from a vast amount of research on phage therapy against various bacterial diseases, that phage provides a stronger shield against stubborn resistant pathogen bacterial strains. They were assumed to be therapeutic due to their bactericidal activity by replication within the target host; this unique pharmacokinetic property of being self-replicating drug gives it a preference over other antibiotics and chemical drugs. Moreover, many phages have been isolated against these extended spectrum strains and patented. The different delivery routes are effective depending upon the target tissues or organ. For example, the oral phage delivery is useful for the treatment GI tract infections, for skin infection, the topical phage application is a suitable and pulmonary bacterial disease can be efficiently treated with the inhalation of phage nebulizer. The most effective, in terms of therapeutic advantage, is the parenteral route of administration, as it provides direct distribution and maximum absorption. However, there has been a little data available on the pharmacokinetic profiling of phage formulations that are being used or are waiting for approval. The pharmacokinetic factors like formulation and concentration are well elaborated in literature; on the other hand, convenient and effective administrative routes require to be explained through further research. Furthermore, to benefit the full from tiny phage particles the factors like kinetics of blood clearance must to be addressed. 


\section{REFERENCES}

Abedon ST. Phage therapy of pulmonary infections. Bacteriophage. 2015;18(5):e1020260.

Abedon ST, Kuhl SJ, Blasdel BG, Kutter EM. Phage treatment of human infections. Bacteriophage. 2011;1(2):66-85.

Barrow P, Lovell M, Berchieri A. Use of lytic bacteriophage for control of experimental Escherichia coli septicemia and meningitis in chickens and calves. Clin Diagn Lab Immunol. 1998;5(3):294-298.

Biswas B, Adhya S, Washart P, Paul B, Trostel AN, Powell B, et al. Bacteriophage therapy rescues mice bacteremic from a clinical isolate of vancomycin-resistant Enterococcus faecium. Infect Immun. 2002;70(1):204-210.

Borie C, Sánchez ML, Navarro C, Ramírez S, Morales MA, Retamales J, et al. Aerosol spray treatment with bacteriophages and competitive exclusion reduces Salmonella Enteritidis infection in chickens. Avian Dis. 2009;53(2):250-254.

Capparelli R, Parlato M, Borriello G, Salvatore P, Iannelli D. Experimental phage therapy against Staphylococcus aureus in mice. Antimicrob Agents And Chemother. 2007;51(8):27652773.

Carmody LA, Gill JJ, Summer EJ, Sajjan US, Gonzalez CF, Young RF, et al. Efficacy of bacteriophage therapy in a model of Burkholderia cenocepacia pulmonary infection. J Infect Dis. 2010;201(2):264-271.

Chan BK, Abedon ST, Loc-Carrillo C. Phage cocktails and the future of phage therapy. Future Microbiol. 2013;8(6):769-783.

Esteban PP, Alves DR, Enright MC, Bean JE, Gaudion A, Jenkins A, et al. Enhancement of the antimicrobial properties of bacteriophage-K via stabilization using oil-in-water nanoemulsions. Biotechnol Prog. 2014;30(4):932-944.

Friman V-P, Ghoul M, Molin S, Johansen HK, Buckling A. Pseudomonas aeruginosa adaptation to lungs of cystic fibrosis patients leads to lowered resistance to phage and protist enemies. PloS One. 2013;8(9):e75380.

Golshahi L, Lynch K, Dennis J, Finlay W. In vitro lung delivery of bacteriophages KS4-M and $\Phi K Z$ using dry powder inhalers for treatment of Burkholderia cepacia complex and Pseudomonas aeruginosa infections in cystic fibrosis. J Appl Microbiol. 2011;110(1):106-117.
Golshahi L, Seed KD, Dennis JJ, Finlay WH. Toward modern inhalational bacteriophage therapy: nebulization of bacteriophages of Burkholderia cepacia complex. J Aerosol Med Pulm Drug Deliv. 2008;21(4):351-360.

Goode D, Allen V, Barrow P. Reduction of experimental Salmonella and Campylobacter contamination of chicken skin by application of lytic bacteriophages. Appl Environm Microbiol. 2003;69(8):5032-5036.

Górski A, Dabrowska K, Hodyra-Stefaniak K, Borysowski J, Miedzybrodzki R, Weber-Dabrowska B. Phages targeting infected tissues: novel approach to phage therapy. Future Microbiol. 2015;10(2):199-204.

Hawkins C, Harper D, Burch D, Änggård E, Soothill J. Topical treatment of Pseudomonas aeruginosa otitis of dogs with a bacteriophage mixture: a before/after clinical trial. Vet Microbiol. 2010;146(3-4):309-313.

Hoe S, Semler DD, Goudie AD, Lynch KH, Matinkhoo S, Finlay WH, et al. Respirable bacteriophages for the treatment of bacterial lung infections. J Aerosol Med Pulm Drug Deliv. 2013;26(6):317-335.

Hraiech S, Brégeon F, Rolain J-M. Bacteriophage-based therapy in cystic fibrosis-associated Pseudomonas aeruginosa infections: rationale and current status. Drug Des Devel Ther. 2015;9:365363. issue number is missing

James CE, Davies EV, Fothergill JL, Walshaw MJ, Beale CM, Brockhurst MA, et al. Lytic activity by temperate phages of Pseudomonas aeruginosa in long-term cystic fibrosis chronic lung infections. ISME J. 2015;9(6):1391-1398.

Khawaldeh A, Morales S, Dillon B, Alavidze Z, Ginn AN, Thomas L, et al. Bacteriophage therapy for refractory Pseudomonas aeruginosa urinary tract infection. J Med Microbiol. 2011;60(Pt 11):1697-1700.

Knoll BM, Mylonakis E. Antibacterial bioagents based on principles of bacteriophage biology: an overview. Clin Infect Dis. 2014;58(4):528-534.

Kumari S, Harjai K, Chhibber S. Topical treatment of Klebsiella pneumoniae B5055 induced burn wound infection in mice using natural products. J Infect Dev Countries. 2010;4(6):367-377. 
Kvachadze L, Balarjishvili N, Meskhi T, Tevdoradze E, Skhirtladze N, Pataridze T, et al. Evaluation of lytic activity of staphylococcal bacteriophage $\mathrm{Sb}-1$ against freshly isolated clinical pathogens. Microb Biotechnol. 2011;4(5):643-650.

Ma Y, Pacan JC, Wang Q, Xu Y, Huang X, Korenevsky A, et al. Microencapsulation of bacteriophage felix O1 into chitosanalginate microspheres for oral delivery. Appl Env Microbiol. 2008;74(15):4799-4805.

Markoishvili K, Djavakhishvili N, Goderdzishvili M, Meipariani A, Chavchanidze Z, Tsitlanadze G, et al. Phagebioderm-new prospects for treatment of wounds and trophic ulcers. Exp Clin Med. 1999;2:83-84. issue number is missing

Matinkhoo S, Lynch KH, Dennis JJ, Finlay WH, Vehring R. Spray-dried respirable powders containing bacteriophages for the treatment of pulmonary infections. J Pharm Sci. 2011;100(12):5197-5205.

Matsuzaki S, Yasuda M, Nishikawa H, Kuroda M, Ujihara T, Shuin T, et al. Experimental protection of mice against lethal Staphylococcus aureus infection by novel bacteriophage фMR11. J Infect Dis. 2003;187(4):613-624.

McVay CS, Velásquez M, Fralick JA. Phage therapy of Pseudomonas aeruginosa infection in a mouse burn wound model. Antimicrob Agents Chemother. 2007;51(6):1934-1938.

Merabishvili M, Pirnay J-P, Verbeken G, Chanishvili N, Tediashvili M, Lashkhi N, et al. Quality-controlled small-scale production of a well-defined bacteriophage cocktail for use in human clinical trials. PloS One. 2009;4(3):e4944.

Merabishvili M, Vervaet C, Pirnay J-P, De Vos D, Verbeken G, Mast J, et al. Stability of Staphylococcus aureus phage ISP after freeze-drying (lyophilization). Plos One. 2013;8(7):e68797.

Międzybrodzki R, Fortuna W, Weber-Dąbrowska B, Górski A. Phage therapy of staphylococcal infections (including MRSA) may be less expensive than antibiotic treatment. Postępy Hig. 2007;61(3):e461-465.

O'Flaherty S, Ross R, Meaney W, Fitzgerald G, Elbreki M, Coffey A. Potential of the polyvalent anti-Staphylococcus bacteriophage $\mathrm{K}$ for control of antibiotic-resistant staphylococci from hospitals. Appl Env Microbiol. 2005;71(4):1836-1842.

Ohtake S, Martin RA, Yee L, Chen D, Kristensen DD, LechugaBallesteros D, et al. Heat-stable measles vaccine produced by spray drying. Vaccine. 2010;28(5):1275-1284.
Oliveira A, Sereno R, Nicolau A, Azeredo J. The influence of the mode of administration in the dissemination of three coliphages in chickens. Poult Sci. 2009;88(4):728-733.

Paisano A, Spira B, Cai S, Bombana A. In vitro antimicrobial effect of bacteriophages on human dentin infected with Enterococcus faecalis ATCC 29212. Oral Microbiol Immunol. 2004;19(5):327-330.

Qadir MI. Phage therapy: A modern tool to control bacterial infections. Pak J Pharm Sci. 2015;28(1):265-270.

Sakandelidze V, Meĭpariani A. Use of combined phages in suppurative-inflammatory diseases. Zh Mikrobiol Epidemiol Immunobiol. 1974;51(6):135-136.

Saussereau E, Vachier I, Chiron R, Godbert B, Sermet I, Dufour N, et al. Effectiveness of bacteriophages in the sputum of cystic fibrosis patients. Clin Microbiol Infect. 2014;20(12):O983-O990.

Singla S, Harjai K, Katare OP, Chhibber S. Bacteriophageloaded nanostructured lipid carrier: Improved pharmacokinetics mediates effective resolution of Klebsiella pneumoniae induced lobar pneumonia. J Infect Dis. 2015;212(2):325-34.

Sulakvelidze A. Phage therapy: an attractive option for dealing with antibiotic-resistant bacterial infections. Drug Discov Today. 2005;10(12):807-809.

Sulakvelidze A, Alavidze Z, Morris JG. Bacteriophage therapy. Antimicrob Agents Chemother. 2001;45(3):649-659.

Tanji Y, Shimada T, Fukudomi H, Miyanaga K, Nakai Y, Unno $\mathrm{H}$. Therapeutic use of phage cocktail for controlling Escherichia coli O157: $\mathrm{H} 7$ in gastrointestinal tract of mice. J Biosci Bioeng. 2005;100(3):280-287.

Uchiyama J, Maeda Y, Takemura I, Chess-Williams R, Wakiguchi $\mathrm{H}$, Matsuzaki S. Blood kinetics of four intraperitoneally administered therapeutic candidate bacteriophages in healthy and neutropenic mice. Microbiol Immunol. 2009;53(5):301-304.

Vandenheuvel D, Lavigne R, Brüssow H. Bacteriophage therapy: advances in formulation strategies and human clinical trials. Annu Rev Virol. 2015;2(1):599-618.

Vandenheuvel D, Singh A, Vandersteegen K, Klumpp J, Lavigne R, Van den Mooter G. Feasibility of spray drying bacteriophages into respirable powders to combat pulmonary bacterial infections. Eur J Pharm Biopharm. 2013;84(3):578-582. 
Phage therapy: progress in pharmacokinetics

Veronese FM, Pasut G. PEGylation, successful approach to drug delivery. Drug Discov Today. 2005;10(21):1451-1458.

Wills QF, Kerrigan C, Soothill JS. Experimental bacteriophage protection against Staphylococcus aureus abscesses in a rabbit model. Antimicrob Agents Chemother. 2005;49(3):1220-1221.
Wright A, Hawkins C, Änggård E, Harper D. A controlled clinical trial of a therapeutic bacteriophage preparation in chronic otitis due to antibiotic-resistant Pseudomonas aeruginosa; a preliminary report of efficacy. Clin Otolaryngol. 2009;34(4):349-357.

Received for publication on $19^{\text {th }}$ June 2017 Accepted for publication on $30^{\text {th }}$ September 2017 